\title{
Redução de proteína bruta com suplementação de aminoácidos, com base no conceito de proteína ideal, em rações para alevinos de tilápia-do-nilo ${ }^{1}$
}

\author{
Marcos Antonio Delmondes Bomfim ${ }^{2 *}$, Eduardo Arruda Teixeira Lanna ${ }^{3}$, Juarez Lopes \\ Donzele $^{3}$, Márvio Lobão Teixeira de Abreu ${ }^{4}$, Felipe Barbosa Ribeiro ${ }^{2}$, Moisés Quadros ${ }^{2}$
}

\author{
1 Projeto financiado pela FAPEMIG. \\ 2 Programa de Pós-graduação em Zootecnia - UFV. Bolsista do CNPq. \\ ${ }^{3}$ Departamento de Zootecnia - DZO/UFV. \\ ${ }^{4}$ Departamento de Zootecnia - DZO/UFPI.
}

RESUMO - Objetivou-se avaliar o efeito da redução da proteína bruta (PB) da ração com suplementação de aminoácidos, com base no conceito de proteína ideal, sobre o desempenho de alevinos de tilápia-do-nilo (Oreochromis niloticus). Utilizaram-se 396 alevinos, linhagem tailandesa, com 0,80 \pm 0,17 g de peso vivo, distribuídos em delineamento de blocos ao acaso, composto de seis tratamentos (32, 31, 30, 29, 28 e 27\% de PB), seis blocos por tratamento e 11 peixes por unidade experimental. As rações foram formuladas para serem isoenergéticas e isolisínicas digestíveis, mantendo-se constantes as relações mínimas dos aminoácidos com a lisina. Os peixes foram mantidos em 36 aquários de 130 L, dotados de abastecimento de água, temperatura controlada e aeração individual, e alimentados à vontade seis vezes ao dia durante 40 dias. A redução do teor de proteína bruta da ração não afetou o ganho de peso, a taxa de crescimento específico, o consumo de ração, o consumo de lisina digestível, o teor de proteína corporal, as taxas de deposição de gordura e de proteína e a eficiência de retenção de nitrogênio dos peixes. Os peixes alimentados com rações com $27 \%$ de PB apresentaram pior conversão alimentar, menor eficiência de utilização da lisina para ganho, menor consumo de nitrogênio e umidade corporal, maior eficiência protéica para ganho e mais alto teor de gordura corporal. O nível de proteína bruta da ração para alevinos de tilápiado-nilo pode ser reduzido em quatro pontos percentuais (de 32 para 28\%), pois essa redução não prejudica o desempenho dos animais, desde que as rações sejam suplementadas com aminoácidos essenciais limitantes.

Palavras-chave: aminoácidos sintéticos, lisina digestível, nutrição protéica, Oreochromis niloticus

\section{Reduction of crude protein with amino acid supplementation, based on ideal protein concept, in diets for Nile tilapia fingerlings}

\begin{abstract}
The effect of decreasing dietary crude protein (CP) with supplementation of amino acids, based on the ideal protein concept on Nile tilapia (Oreochromis niloticus) fingerlings performance was evaluated. A total of 396 fingerlings from Thai strain, with $0.80 \pm 0.17 \mathrm{~g}$ of BW, was allotted to a randomized block design, with six levels of CP (32, 31, 30, 29, 28 and $27 \%$ of CP) in the diets, six replications with 11 fish each. The diets were formulated to be isocaloric and digestible isolysine, remaining constant the amino acids to lysine minimum ratio. The fish were kept in 36 aquariums of $130 \mathrm{~L}$, equipped with water supply, controlled temperature and individual aeration, and ad libitum fed six times a day for 40 days. The reduction of CP content of the diet did not affect weight gain, specific growth rate, feed intake, digestible lysine intake, body protein content, fat and protein deposition rates and nitrogen retention efficiency of fishes. The fish fed diets with $27 \%$ of CP lower feed: gain ratio, lysine efficiency for gain, nitrogen intake and body water and higher protein efficiency for gain and body fat content. The level of crude protein of the diet for Nile tilapia fingerlings can be reduced by four percentage points (from 32 to $28 \%$ ), without negative effect on the performance of the animals, since the diets are supplemented with essential limiting amino acids.
\end{abstract}

Key Words: digestible lysine, Oreochromis niloticus, protein nutrition, synthetic amino acids

\section{Introdução}

Um dos grandes desafios da piscicultura intensiva é conciliar a obtenção de alta produtividade com menor descarga de resíduos no ambiente aquático, principalmente de nitrogênio e fósforo, uma vez que, neste sistema, os peixes dependem exclusivamente de rações balanceadas (Furuya, 2001; Furuya et al., 2001, 2005; Lanna et al., 2005; Sugiura et al., 2001).

Este artigo foi recebido em 25/1/2007 e aprovado em 14/4/2008. 
A tilápia-do-nilo (Oreochromis niloticus) caracteriza-se por ser de baixo nível trófico (onívora) e por ter boa aceitação no mercado consumidor. Tem se destacado na aqüicultura mundial por apresentar crescimento rápido, alta rusticidade, capacidade de adaptação a diferentes condições climáticas, carne de ótima qualidade, e por não apresentar espinhos na forma de "Y" no seu filé. Além disso, pesquisas têm demonstrado que esta espécie tolera altos níveis de carboidratos nas rações, o que favorece a utilização de fontes protéicas alternativas à farinha de peixe (Furuya et al., 2000, 2001, 2005; Boscolo et al., 2002a, b).

Como as rações formuladas para atender as exigências dietéticas em proteína bruta para esta espécie normalmente contêm elevados níveis de aminoácidos não limitantes (dispensáveis e indispensáveis), o teor de nitrogênio excretado no meio tem sido elevado. Diminuir a concentração de proteína da ração concomitantemente com suplementação de aminoácidos limitantes pode ser uma estratégia para redução do teor de nitrogênio excretado no meio ambiente, sem prejudicar o desempenho dos peixes (Rollin et al., 2003; Boisen, 2003; Furuya et al., 2005; Lanna et al., 2005; Yamamoto et al., 2005).

Há evidências, contudo, de que a utilização excessiva de aminoácidos sintéticos nas rações de baixo teor protéico pode não garantir a mesma eficiência de utilização dos aminoácidos oriundos de proteína intacta (NRC, 1993; Cowey, 1994; El-Husseiny etal., 2002; Dabrowski \& Guderley, 2002; Dabrowski et al., 2003).

A menor eficiência de utilização da fração nitrogenada das rações com níveis excessivos de aminoácidos livres pode estar relacionada à maior capacidade de lixiviação no ambiente aquático, maior taxa de evacuação estomacal e rápida absorção em relação aos aminoácidos da "proteína intacta” do alimento, acarretando desbalanço no pool de aminoácidos e/ou em quantidades incompatíveis à capacidade/velocidade de síntese protéica nos tecidos especializados. Conseqüentemente, os valores de exigência em aminoácidos obtidos em estudos de dose-resposta, que normalmente utilizam elevados níveis de aminoácidos sintéticos, podem ficar superestimados, principalmente quando os animais são alimentados com menos freqüência (Schuhmacher et al., 1997; Zarate \& Lovell, 1997; Barroso et al., 1999; Zarate et al., 1999; Dabrowski et al., 2003).

Por outro lado, apesar da carência de informações disponíveis, há evidências de que a inclusão de níveis moderados de aminoácidos sintéticos nas rações pode não afetar o desempenho tanto quanto a eficiência alimentar dos peixes (Yamamoto et al., 2005; Furuya et al., 2005).

Assim, avaliaram-se neste estudo os efeitos da redução da proteína bruta com a suplementação de aminoácidos, com base no conceito de proteína ideal, em rações para alevinos de tilápia-do-nilo (Oreochromis niloticus).

\section{Material e Métodos}

O experimento foi conduzido entre os meses de outubro e dezembro de 2004, no Laboratório de Nutrição de Peixes do Departamento de Zootecnia da Universidade Federal de Viçosa (UFV), em Viçosa, Minas Gerais e teve duração de 40 dias.

Foram utilizados 396 alevinos revertidos de tilápia (Oreochromis niloticus), linhagem tailandesa, com peso inicial de 0,80 $\pm 0,17 \mathrm{~g}$, em um delineamento em blocos ao acaso, composto de seis tratamentos, seis blocos por tratamento e 11 peixes por unidade experimental. Para a formação dos blocos, considerou-se o peso médio inicial dos peixes.

Os tratamentos foram constituídos de seis rações experimentais contendo 32, 31, 30, 29, 28 ou 27\% de proteína bruta (PB), isoenergéticas, isocálcicas e isofosfóricas, com a mesma proporção entre as fontes protéicas. As rações (Tabela 1) foram formuladas para atender às exigências nutricionais mínimas sugeridas pelo NRC (1993), exceto para a lisina digestível. O nível de lisina digestível usado foi de 1,50\%, conforme estabelecido por Jackson \& Capper (1982) e, para que as rações fossem isolisínicas digestíveis, adicionou-se lisina sintética (L-lisina-HCl) às rações. Os demais aminoácidos foram suplementados às rações para que suas relações com a lisina digestível não ficassem inferiores a 63\% para metionina + cistina digestíveis, 74\% para treonina digestível e 20\% para triptofano digestível, calculadas a partir dos valores de exigência descritos no NRC(1993).

Os alevinos foram mantidos em 36 aquários de polietileno, com capacidade volumétrica de 150 litros e volume útil de 130 litros, dotados de sistemas individuais de aeração, abastecimento de água e escoamento de fundo, dispostos em sistema de recirculação e renovação mínima de água de $25 \%$ por dia.

A água de abastecimento dos aquários foi proveniente do sistema de tratamento de água da Universidade Federal de Viçosa - UFV, previamente declorada e aquecida por resistências elétricas, com temperatura controlada por termostato.

A temperatura da água foi mantida em torno de $28^{\circ} \mathrm{C}$ e aferida diariamente, às $7 \mathrm{~h} 30$ e $17 \mathrm{~h} 30$, com auxílio de um termômetro de bulbo de mercúrio, graduado de 0 a $50^{\circ} \mathrm{C}$. Os controles do $\mathrm{pH}$ e do teor de oxigênio dissolvido na água foram realizados a cada sete dias, por meio de um potenciômetro e oxímetro. 
Tabela 1 - Composição percentual e química das rações experimentais (matéria natural)

\begin{tabular}{|c|c|c|c|c|c|c|}
\hline Ingrediente (\%) & \multicolumn{6}{|c|}{ Nível de proteína bruta (\%) } \\
\hline Farelo de soja & 53,72 & 51,83 & 49,95 & 48,06 & 46,18 & 44,29 \\
\hline Glúten de milho 60 & 8,12 & 7,83 & 7,55 & 7,26 & 6,98 & 6,69 \\
\hline Óleo de soja & 2,04 & 2,19 & 2,33 & 2,48 & 2,62 & 2,77 \\
\hline Amido de milho & 1,00 & 3,95 & 6,88 & 9,83 & 12,76 & 15,71 \\
\hline L-treonina $(98,5 \%)$ & 0,00 & 0,04 & 0,08 & 0,13 & 0,17 & 0,21 \\
\hline Calcário calcítico & 0,08 & 0,06 & 0,05 & 0,03 & 0,02 & 0,00 \\
\hline Fosfato bicálcico & 2,90 & 2,95 & 3,00 & 3,05 & 3,10 & 3,15 \\
\hline Vitamina $C^{3}$ & 0,05 & 0,05 & 0,05 & 0,05 & 0,05 & 0,05 \\
\hline Suplemento vitamínico e mineral ${ }^{4}$ & 0,50 & 0,50 & 0,50 & 0,50 & 0,50 & 0,50 \\
\hline Sal comum & 0,50 & 0,50 & 0,50 & 0,50 & 0,50 & 0,50 \\
\hline Proteína digestível (\%) & 29,00 & 28,10 & 27,20 & 26,30 & 25,40 & 24,50 \\
\hline Energia digestível $(\mathrm{kcal} / \mathrm{kg})^{2}$ & 3.000 & 3.000 & 3.000 & 3.000 & 3.000 & 3.000 \\
\hline Extrato etéreo (\%) & 4,15 & 4,22 & 4,30 & 4,37 & 4,45 & 4,52 \\
\hline Ácido linoléico (\%) & 2,21 & 2,25 & 2,29 & 2,33 & 2,37 & 2,41 \\
\hline Cálcio total (\%) & 0,93 & 0,93 & 0,93 & 0,93 & 0,93 & 0,93 \\
\hline Fósforo disponível $(\%)^{2}$ & 0,60 & 0,60 & 0,60 & 0,60 & 0,60 & 0,60 \\
\hline Lisina digestível $(\%)^{2}$ & 1,50 & 1,50 & 1,50 & 1,50 & 1,50 & 1,50 \\
\hline Met. + Cist. digestível $(\%)^{2}$ & 0,95 & 0,95 & 0,95 & 0,95 & 0,95 & 0,95 \\
\hline Treonina digestível $(\%)^{2}$ & 1,11 & 1,11 & 1,11 & 1,11 & 1,11 & 1,11 \\
\hline Triptofano digestível $(\%)^{2}$ & 0,36 & 0,35 & 0,34 & 0,32 & 0,31 & 0,30 \\
\hline Isoleucina digestível $(\%)^{2}$ & 1,26 & 1,22 & 1,17 & 1,13 & 1,08 & 1,04 \\
\hline
\end{tabular}

${ }^{1}$ Composição calculada segundo Rostagno et al. (2000).

2 Valores estimados com base nos coeficientes de digestibilidade dos ingredientes para os aminoácidos e o fósforo, de acordo com Rostagno et al. (2000) e Furuya (2000), e de energia, de acordo com Boscolo et al. (2002c) e Pezzato et al. (2002).

3 Vit. C: sal cálcica 2-monofosfato de ácido ascórbico, $42 \%$ de princípio ativo.

${ }^{4}$ Composição por quilograma do produto: vit. A - 1.200 .000 Ul; vit. $D_{3}-200.000$ Ul; vit. E $-1.200 \mathrm{mg}$; vit. $K_{3}-2.400 \mathrm{mg}$; vit. $B_{1}-4.800 \mathrm{mg}$; vit. $B_{2}-4.800 \mathrm{mg}$ vit. $\mathrm{B}_{6}-4.800 \mathrm{mg}$; vit. $\mathrm{B}_{12}-4.800 \mathrm{mg}$; vit. $\mathrm{C}-48 \mathrm{~g}$; ácido fólico $-1.200 \mathrm{mg}$; pantotenato de cálcio $-12.000 \mathrm{mg}$; vit. C - $48.000 \mathrm{mg}$; biotina - $48 \mathrm{mg}$; cloreto de colina - 108 g; niacina - 24.000 mg; Fe - 50.000 mg; Cu - 3.000 mg; Mn - 20.000 mg; Zn - 30.000 mg; I - 100 mg; Co - 10 mg; Se - 100 mg.

O fotoperíodo foi mantido em 12 horas de luz, por meio de iluminação proveniente de lâmpadas mistas, controlado por timer automático.

As rações experimentais foram peletizadas e fornecidas diariamente, em seis alimentações $(8,10,12,14$, 16 e 18 h), de modo que, em cada alimentação, as rações foram oferecidas em pequenas quantidades, com sucessivos repasses, a fim de possibilitar a ingestão máxima, sem perdas, até a aparente saciedade, e diminuir a possibilidade de lixiviações.

A limpeza dos aquários foi feita duas vezes por dia, para retirada das fezes por sifonagem, após as leituras da temperatura da água.

Foram avaliados os seguintes parâmetros: ganho de peso, taxa de crescimento específico, taxa de sobrevivência, consumo de ração, consumo de lisina digestível, consumo de nitrogênio, conversão alimentar, eficiência protéica para ganho, eficiência de lisina para ganho, deposição diária de proteína e gordura corporais, composição química corporal (teores de umidade, proteína e gordura) e eficiência de retenção de nitrogênio.

Para determinação da taxa de crescimento específico (TCE), foi empregada a equação abaixo, utilizando-se transformações logarítmicas.

$$
\begin{gathered}
\log \text { natural do peso final }(g)-\log \text { natural } \\
\text { do peso inicial (g) }
\end{gathered}
$$

$\mathrm{TCE}=$ $\mathrm{x} 100$

\section{Período experimental (dias)}

As eficiências de utilização de proteína e lisina para ganho foram calculadas dividindo-se o ganho de peso dos peixes pelo consumo de proteína bruta ou de lisina digestível, respectivamente.

No início do experimento, 80 peixes foram anestesiados e sacrificados e, ao final do experimento, oito peixes com pesos mais próximos ao peso médio da respectiva unidade foram sacrificados, de forma idêntica, para análises corporais. 
As análises bromatológicas das rações e das amostras dos peixes foram realizadas no Laboratório de Nutrição Animal do Departamento de Zootecnia (LNA/DZO) da Universidade Federal de Viçosa - UFV, conforme procedimentos descritos por Silva \& Queiroz (2003).

As deposições de proteína e de gordura corporais foram calculadas pela diferença da proteína ou gordura corporal final e inicial, respectivamente, em mg, dividida pelo período experimental, em dias.

A eficiência de retenção de nitrogênio, expressa em porcentagem, foi calculada pela diferença do nitrogênio corporal final e inicial, dividido pelo nitrogênio total consumido, multiplicado por 100 .

As análises estatísticas foram realizadas pelo programa SAEG - Sistema de Análises Estatísticas e Genéticas (UFV, 1997).

Os dados foram analisados por meio de análise de variância a 5\% de probabilidade e, no caso de diferença estatística, para a comparação das médias obtidas pelos peixes alimentados com rações de menor teor protéico em relação aos peixes do tratamento com maior teor de PB, foi utilizado o teste Dunnett.

\section{Resultados e Discussão}

O sistema de abastecimento de água e de aeração possibilitou a manutenção da temperatura e da aeração durante o período experimental. Foram obtidos os valores de $28,0 \pm 0,83^{\circ} \mathrm{C}$ para temperatura da água, de $6,6 \pm 0,14$ para o pH e de 6,4 $\pm 0,40 \mathrm{mg} / \mathrm{L}$ para o oxigênio dissolvido. Esses valores encontram-se na faixa recomendada para a criação desta espécie, segundo Kubitza (2000).

A redução do teor de proteína bruta (PB) da ração não influenciou $(\mathrm{P}>0,05)$ o ganho de peso, a taxa de crescimento específico, o consumo de ração, o consumo de lisina digestível e a taxa de sobrevivência dos peixes (Tabela 2), apesar da redução numérica observada no ganho de peso, na taxa de crescimento específico e no consumo de ração dos peixes alimentados com o nível inferior de proteína bruta (27\%) em relação aos valores obtidos com a ração testemunha.

Uma vez que as rações foram isolisínicas e isoenergéticas, a ausência de efeito significativo no consumo de ração implicou em diminuição no consumo de nitrogênio e em elevação da eficiência protéica para ganho à medida em que os níveis de PB da ração foram reduzidos. Observou-se que a redução do teor de PB das rações para 28 e 27\% resultou em peixes com menores $(\mathrm{P}<0,01)$ consumos de nitrogênio e maiores $(\mathrm{P}<0,01)$ eficiências protéicas para ganho, em relação aos alimentados com a ração contendo $32 \%$ de $P B$, observando-se que os peixes alimentados com rações contendo níveis de 31, 30 e 29\% de PB apresentaram valores similares à ração testemunha.

A taxas de crescimento de $7,3 \%$ ao dia dos peixes alimentados com a ração com $27 \%$ de $\mathrm{PB}$ foram próximas à observada por Lanna et al. (2005), de 7,8\% ao dia, e inferiores à observada por Furuya et al. (2000), de 8,7\% ao dia. Entretanto, foram superiores aos valores variáveis de 3,2 a 5,5\% ao dia observados por Boscolo et al. (2002a), Hisano et al. (2003), Furuya et al. (2005), Boscolo et al. (2006) e Furuya et al. (2006) em tilápias da mesma linhagem e mesma categoria de peso. Esses resultados indicam que as rações suplementadas com aminoácidos livres, mesmo com níveis inferiores de proteína bruta em relação às exigências de 32\% para a espécie, segundo Furuya et al. (2000), foram suficientes para potencializar o desempenho dos animais.

Efeitos similares de desempenho, obtidos com rações de baixo teor protéico suplementadas com aminoácidos livres, também foram demonstrados em trutas (Oncorhinchus mykiss) por Yamamoto et al. (2005); em tilápias por Furuya et al. (2005) e em suínos por Ferreira et al. (2003) e por Orlando et al. (2005). Por outro lado, Li \& Robinson (1998),

Tabela 2 - Desempenho de alevinos de tilápia-do-nilo alimentados com rações contendo diversos teores de proteína

\begin{tabular}{|c|c|c|c|c|c|c|c|}
\hline \multirow[t]{2}{*}{ Parâmetro } & \multicolumn{6}{|c|}{ Nível de proteína bruta (\%) } & \multirow[t]{2}{*}{$\mathrm{CV}(\%)$} \\
\hline & 32 & 31 & 30 & 29 & 28 & 27 & \\
\hline Peso inicial (g) & 0,79 & 0,80 & 0,79 & 0,80 & 0,80 & 0,81 & 1,85 \\
\hline Ganho de peso (g) & 15,52 & 14,63 & 14,91 & 14,72 & 14,50 & 13,31 & 10,69 \\
\hline Taxa de crescimento específico (\%/dia) & 7,58 & 7,41 & 7,50 & 7,41 & 7,36 & 7,26 & 3,81 \\
\hline Taxa de sobrevivência (\%) & 89,39 & 95,46 & 93,94 & 98,49 & 90,91 & 96,97 & 6,41 \\
\hline Consumo de ração (g) & 16,92 & 15,87 & 16,78 & 16,40 & 16,67 & 15,46 & 8,87 \\
\hline Consumo de lisina digestível (mg) & 254 & 238 & 252 & 246 & 249 & 232 & 8,87 \\
\hline Consumo de nitrogênio (mg) & 866 & 787 & 805 & 761 & $745^{*}$ & $668^{*}$ & 8,69 \\
\hline Conversão alimentar (g/g) & 1,09 & 1,09 & 1,13 & 1,12 & 1,16 & $1,18^{*}$ & 3,26 \\
\hline Eficiência protéica para ganho (g/g) & 2,86 & 2,97 & 2,96 & $3,08^{*}$ & $3,09^{*}$ & $3,15^{*}$ & 3,21 \\
\hline Eficiência de lisina para ganho (g/g) & 61,08 & 61,37 & 59,11 & 59,48 & 57,69 & $56,75^{*}$ & 3,18 \\
\hline
\end{tabular}

CV- coeficiente de variação.

* Média na mesma linha que difere $(P<0,05)$ da ração testemunha pelo teste Dunnett. 
avaliando os efeitos da redução protéica de 32 para 24\% com ou sem suplementação de lisina e/ou metionina sintéticas para bagres-do-canal (Ictalurus punctatus), não observaram melhora no desempenho dos animais, o que, provavelmente, foi ocasionado pela deficiência de outros aminoácidos limitantes.

A maior eficiência protéica para ganho com a redução do teor de PB da ração pode ser atribuída à redução dos aminoácidos excedentes às exigências do animal que, provavelmente, não contribuiriam para a formação de tecido magro e seriam catabolizados. Esses resultados corroboram a teoria de que os peixes, assim como suínos e aves, não possuem exigência de proteína, mas dependem de adequado balanceamento entre aminoácidos dispensáveis e indispensáveis para seus processos de mantença e produção (Boisen et al., 2000; Boisen, 2003; Orlando et al., 2005; Furuya et al., 2005; Yamamoto et al., 2005).

Apenas os peixes alimentados com a ração contendo $27 \%$ de $\mathrm{PB}$ apresentaram pior $(\mathrm{P}<0,01)$ conversão alimentar e eficiência de lisina digestível para ganho em relação aos alimentados com a ração contendo 32\% de PB. Essa piora na conversão alimentar e na eficiência de utilização de lisina para ganho dos peixes alimentados com rações com teor protéico reduzido e suplementadas com aminoácidos sintéticos tem sido atribuída à limitada eficiência na utilização de rações suplementadas com níveis excedentes de aminoácidos sintéticos, à possibilidade lixiviação dos aminoácidos no ambiente aquático; ou ao desbalanceamento do perfil aminoacídico dietético (Schuhmacher et al., 1997; Zarate \& Lovell, 1997; Zarate et al., 1999; Dabrowski et al., 2003; Lanna et al., 2005).

Têm-se observado que os aminoácidos sintéticos apresentam maiores velocidades de evacuação estomacal e absorção dos aminoácidos oriundos da proteína “intacta”, o que pode resultar em elevação excessiva e precoce das concentrações plasmáticas desses aminoácidos nos sítios de síntese protéica, aumentando seu catabolismo, e acarretando desequilíbrio no pool de aminoácidos para a síntese protéica e ter conseqüências na utilização dos demais aminoácidos (Tantikitti \& March, 1995; Schuhmacher et al., 1997; Zarate \& Lovell, 1997; Zarate et al., 1999; Aoki et al., 2001).

Por outro lado, esses efeitos podem ser reduzidos com a utilização de níveis moderados de aminoácidos sintéticos nas rações (El-Husseiny et al., 2002) e com intervalos mais curtos de alimentação (mínimo de quatro vezes/dia), o que pode estabilizar a concentração plasmática dos aminoácidos e compatibilizar a capacidade ou velocidade de síntese protéica pelos tecidos especializados, aumentando a utili- zação da fração nitrogenada (Tantikitti \& March, 1995; Zarate et al., 1999; Barroso et al., 1999; Rodehutscord et al., 2000; Lanna, et al., 2005).

Nesta pesquisa, como o alimento foi peletizado e fornecido seis vezes ao dia em quantidades pequenas e em repasses sucessivos para garantir a rápida e completa ingestão das rações e não foram observadas sobras significativas durante os repasses em cada horário de alimentação, é pouco provável que tenha ocorrido lixiviação de aminoácidos sintéticos e/ou desbalanços aminoacídicos nos sítios de síntese protéica em quantidades significativas que pudessem comprometer a conversão alimentar e a eficiência de utilização de lisina dos peixes alimentados com a ração com $27 \%$ de $\mathrm{PB}$. Além disso, apesar de não terem sido utilizados aditivos com características aglutinantes, o amido do milho pode também ter contribuído para reduzir a lixiviação dos aminoácidos, em virtude de suas características aglutinantes (Cantelmo et al., 1999).

A redução nos valores de conversão alimentar e da eficiência de lisina para ganho pode ter sido decorrente da relação triptofano:lisina digestível usada, de 20\% (NRC, 1993). Esta relação pode ter sido subestimada, uma vez que a relação dos demais aminoácidos na ração com $27 \%$ de PB foram iguais à da ração testemunha (metionina + cistina e treonina) ou superiores à relação mínima estabelecida no NRC(1993).

Outro fator que pode aumentar as exigências dietéticas de triptofano é o desafio sanitário, que desencadeia maior ativação do sistema imune. Tem-se verificado redução significativa nas concentrações plasmáticas de triptofano em suínos acometidos por diferentes doenças ou estados inflamatórios, o que sugere aumento da exigência desse aminoácido para síntese de proteínas de fase aguda, durante a estimulação do sistema imune (Melchior et al., 2004; Machado \& Fontes, 2005). Assim, nestes casos, fica evidente a necessidade de uma elevação da relação triptofano:lisina para atender essa demanda e isto pode ter sido a causa dos piores resultados obtidos pelos peixes alimentados com a ração de menor teor protéico.

Verificou-se que a redução do teor protéico da ração não influenciou $(\mathrm{P}>0,05)$ o teor de proteína corporal dos peixes (Tabela 3$)$, porém os peixes alimentados com rações contendo $27 \%$ de proteína bruta apresentaram menores $(\mathrm{P}<0,05)$ teores de umidade corporal em relação aos alimentados com ração contendo 32\% de PB. Os animais alimentados com rações contendo os demais níveis protéicos apresentaram valores similares $(\mathrm{P}>0,05)$ aos obtidos com a ração testemunha.

Com exceção dos peixes alimentados com as rações contendo 31\% de proteína bruta, a redução do teor de PB 
Tabela 3 - Composição corporal, deposições de proteína e gordura corporais e eficiência de retenção de nitrogênio de alevinos de tilápiado-nilo alimentados com rações contendo divesos teores de proteína

\begin{tabular}{|c|c|c|c|c|c|c|c|c|}
\hline \multirow[t]{2}{*}{ Parâmetro } & \multicolumn{7}{|c|}{ Nível de proteína bruta (\%) } & \multirow[t]{2}{*}{ CV (\%) } \\
\hline & Inicial & 32 & 31 & 30 & 29 & 28 & 27 & \\
\hline Umidade corporal $(\%)^{1}$ & 79,09 & 75,92 & 75,20 & 74,83 & 74,96 & 75,02 & $74,52^{*}$ & 0,94 \\
\hline Gordura corporal $(\%)^{1}$ & 5,60 & 7,94 & 8,67 & $9,18^{*}$ & $9,09^{*}$ & $9,08^{*}$ & $9,36^{*}$ & 7,90 \\
\hline Proteína corporal $(\%)^{1}$ & 11,33 & 12,72 & 12,62 & 12,29 & 12,20 & 12,11 & 12,52 & 3,62 \\
\hline Deposição de gordura corporal (mg/dia) & - & 30,84 & 31,97 & 34,82 & 34,59 & 33,71 & 31,66 & 15,62 \\
\hline Deposição protéica (mg/dia) & - & 50,10 & 46,34 & 46,22 & 45,13 & 44,15 & 42,11 & 11,59 \\
\hline Eficiência de retenção de nitrogênio (\%) & - & 36,64 & 37,71 & 36,42 & 37,75 & 37,66 & 39,72 & 4,82 \\
\hline
\end{tabular}

CV- coeficiente de variação.

* Média na mesma linha difere $(P<0,05)$ da ração testemunha pelo teste Dunnett.

1 Matéria natural.

resultou em peixes com maiores $(\mathrm{P}<0,05)$ teores de gordura corporal. Menor teor de gordura corporal dos peixes alimentados com a ração de maior nível protéico (menor relação ED:PB) também foi observado em trutas Oncorhinchus mykiss) por Yamamoto et al. (2005). Em ambos os casos, esses resultados podem estar relacionados à maior quantidade de aminoácidos excedentes para o catabolismo (Dabrowski \& Guderley, 2002), o que pode resultar em maior incremento calórico e menor fração excedente de energia líquida depositada na forma de gordura corporal (Bureau et al., 2000; Noblet, 2001).

Não foram observadas diferenças $(\mathrm{P}>0,05)$ entre as rações quanto às deposições de gordura e proteína corporal diária e à eficiência de retenção de nitrogênio.

Embora os peixes alimentados com as rações contendo níveis mais baixos de proteína bruta tenham apresentado maior teor de gordura corporal, seus menores ganhos de peso, em valores absolutos, parecem ter influenciado o fato de não terem sido detectadas diferenças significativas na deposição de gordura corporal. Contudo, os peixes alimentados com os níveis inferiores de PB apresentaram menores deposições de proteína corporal, em valores absolutos, em comparação aos alimentados com níveis maiores de PB, e a falta de diferença estatística para essa variável pode ter sido ocasionada pelo elevado coeficiente de variação.

Esperava-se melhora da eficiência de retenção de nitrogênio nos peixes alimentados com as rações de baixos níveis protéicos, similar ao obtido em outras pesquisas com tilápias (Furuya et al., 2005) e trutas arco-íris (Yamamoto et al., 2005). Entretanto, como no cálculo desta variável também se considera o consumo de ração, a pior conversão alimentar nestes peixes pode justificar o fato de não terem sido detectadas diferenças estatísticas entre as rações.

Ressalta-se que a redução do teor de PB com suplementação aminoacídica, desde que não excessiva, constitui uma estratégia alimentar eficaz na redução da excreção de nitrogênio para o ambiente, sem afetar significativamente o ganho de peso (Ferreira et al., 2003; Orlando et al., 2005; Furuya et al., 2005; Yamamoto et al., 2005), uma vez que aumenta a utilização protéica para ganho de peso por reduzir os níveis excedentes dos aminoácidos não limitantes das rações.

\section{Conclusões}

A redução de quatro pontos percentuais (de 32 para 28\%) no nível de proteína bruta da ração para alevinos de tilápia-do-nilo não prejudica o desempenho dos animais, desde que as rações sejam devidamente suplementadas com aminoácidos essenciais limitantes.

\section{Agradecimentos}

À Ajinomoto Biolatina Indústria e Comércio Ltda., pela ajuda financeira, como co-financiadora, e pelo fornecimento dos aminoácidos sintéticos e aminogramas.

\section{Literatura Citada}

AOKI, H.; AKIMOTO, A.; WATANABE, T. Periodical changes of plasma free amino acid levels and feed digesta in yellowtail after feeding non-fish meal diets with or without supplemental crystalline amino acids. Fisheries Science, v.67, p.614-618, 2001.

BARROSO, J.B.; PERAGÓN, J.; GARCÍA-SALGUERO, L. et al. Variations in the kinetic behavior of the NADPH-production systems in different tissues of the trout when fed on an amino-acidbased diet at different frequencies. The International Journal of biochemistry \& Cell Biology, v.31, p.277-290, 1999.

BOISEN, S.; HVELPLUND, T.; WEISBJERG, M.R. Ideal amino acid profiles as a basis for feed protein evaluation. Livestock Production Science, v.64, p.239-251, 2000.

BOISEN, S. ideal dietary amino acid profiles for pigs. In: D’MELLO, J.P.F. (Ed.) Amino acid in farm animal nutrition. Wallingford: CAB International, 2003. p.157-168.

BOSCOLO, W.R.; HAYASHI, C.; MEURER, F. Desempenho e características de carcaça de machos revertidos de tilápias do Nilo (Oreochromis niloticus, L.), linhagens tailandesa e comum, nas fases inicial e de crescimento Revista Brasileira de Zootecnia, v.31, n.2, p.539-545, 2002a. 
BOSCOLO, W.R.; HAYASHI, C.; MEURER, F. Farinha de varredura de mandioca (Manihot esculenta) na alimentação de alevinos de tilápia-do-nilo (Oreochromis niloticus L.). Revista Brasileira de Zootecnia, v.31, n.2, p.546-551, 2002b.

BOSCOLO, W.R.; HAYASHI, C.; MEURER, F. Digestibilidade aparente da energia e nutrientes de alimentos convencionais e alternativos para a tilápia-do-nilo (Oreochromis niloticus, L.) Revista Brasileira de Zootecnia, v.31, n.2, p.539-545, 2002c.

BOSCOLO, W.R.; FEIDEN, A.; SIGNOR, A. et al. Energia digestível para alevinos de tilápia-do-nilo (Oreochromis niloticus, L.) Revista Brasileira de Zootecnia, v.35, n.3, p.629-633, 2006.

BUREAU, B.P.; AZEVEDO, P.A.; TAPIA-SALAZAR, M. et al. Pattern and cost of growth and nutrient deposition in fish and shrimp: Potential implications and applications. In: AVANCES EN NUTRICIÓN ACUÍCOLA, 5., SIMPOSIUM INTERNACIONAL DE NUTRICIÓN ACUÍCOLA, 5., 2000, Mérida, Yucatán, Mexico. Memorias... Mérida: 2000. (CD-ROM).

CANTELMO, O.A.; PEZZATO, L.E.; BARROS, M.M. et al. Influência de diferentes aglutinantes na digestibilidade aparente da matéria seca e da proteína, no pacu (Piaractus mesopotamicus) arraçoado com rações elaboradas sem ou com vapor. Acta Scientiarum, v.21, n.2, p.277-282, 1999.

COWEY, C.B. Amino acid requirements of fish: a critical appraisal of present values. Aquaculture, v.124, p.1-11, 1994.

DABROWSKI, K.; GUDERLEY, H. Intermediary metabolism. In: HALVER, J.E.; HARDY, R.W. (Eds.) Fish nutrition. 3.ed. Washington, D.C.: Academic Press, 2002. p.309-365.

DABROWSKI, K.; LEE, K.; RINCHARD, J. The smallest vertebrate, teleost fish, can utilize synthetic dipeptide-based diets. Journal Nutrition, v.133, p.4225-4229, 2003.

EL-HUSSEINY, O.M.; GODA, A.M.A.S.; SULOMA, A.M. Utilization of amino acids in Nile tilapia (Oreochromis niloticus) fry. 1. Utilization efficiency of synthetic amino acid by Nile tilapia fry. Veterinary Medical Journal Giza, v.50, n.1, p.47-59, 2002.

FERREIRA, R.A.; OLIVEIRA, R.F.M.; DONZELE, J.L. et al. Redução da proteína bruta da ração para suínos machos castrados dos 15 aos $30 \mathrm{~kg}$ mantidos em termoneutralidade. Revista Brasileira de Zootecnia, v.32, n.6, p.1639-1646, 2003.

FURUYA, W.M.; HAYASHI, C.; FURUYA, V.R.B. et al. Exigência de proteína para alevino revertido de tilápia-do-nilo (Oreochromis niloticus). Revista Brasileira de Zootecnia, v.26, n.6, p.19121917, 2000 (supl. 1).

FURUYA, W.N. Digestibilidade aparente de aminoácidos e substituição da proteína da farinha de peixe pela proteína do farelo de soja com base no conceito da proteína ideal em rações para tilápia-do-nilo (Oreochromis niloticus). Botucatu: Universidade Estadual Paulista, 2000. 69p. Dissertação (Doutorado em Zootecnia) - Universidade Estadual Paulista, 2000.

FURUYA, W.M. Alimentos ambientalmente corretos para piscicultura. In: REUNIÃO ANUAL DA SOCIEDADE BRASILEIRA DE ZOOTECNIA, 38., 2001, Piracicaba. Anais... Piracicaba: 2001. (CD-ROM).

FURUYA, W.N.; GONÇALVES, S.G.; FURUYA, V.R.B. et al. Fitase na alimentação de tilápia-do-nilo (Oreochromis niloticus). Desempenho e digestibilidade. Revista Brasileira de Zootecnia, v.30, n.3, p.924-929, 2001 (supl. 1).

FURUYA, W.M.; BOTARO, D.; MACEDO, R.M.G. et al. Aplicação do conceito de proteína ideal para redução dos níveis de proteína em dietas para tilápia-do-nilo (Oreochromis niloticus). Revista Brasileira de Zootecnia, v.34, n.5, p.1433-1441, 2005.

FURUYA, W.M.; BOTARO, D.; SANTOS, V.G. et al. Exigências de lisina digestível para juvenis de tilápia-do-Nilo. Revista Brasileira de Zootecnia, v.35, n.3, p.937-942, 2006 (supl.).

HISANO, H.; GONÇALVES, G.S.; ZUANON, J.A.S. et al. Substituição da proteína do farelo de soja pela proteína do glúten de milho em rações para alevinos de tilápia-do-nilo. Acta Scientiarum, v.22, n.2 p.255-260, 2003.
JACKSON, A.J.; CAPPER, B.S. Investigations into the requirements of the tilapia Sarotherodon mossambicus for dietary methionine, lysine and arginine in semi-synthetic diets. Aquaculture, v.29, p.289-297, 1982.

KUBITZA, F. Tilápia: tecnologia e planejamento na produção comercial. Jundiaí: F. Kubitza, 2000. 285p.

LANNA, E.A.T.; QUADROS, M.; BOMFIM, M.A.D. et al. Freqüência de alimentação em alevinos de tilápia-do-nilo (Oreochromis niloticus) utilizando dietas de baixo teor protéico suplementadas com aminoácidos - resultados preliminares. IN: REUNIÃO ANUAL DA SOCIEDADE BRASILEIRA DE ZOOTECNIA, 42., 2005, Goiânia. Anais... Goiânia, 2005. (CD-ROM).

LI, M.H.; ROBINSON, E.H. Effects of supplemental lysine and methionine in low protein diets on weight gain and body composition of young channel catfish Ictalurus punctatus. Aquaculture, v.163, p.297-307, 1998.

MACHADO, G.S.; FONTES, D.O. Relação entre as exigências nutricionais e o sistema imune em suínos. In: SIMPÓSIO INTERNACIONAL SOBRE EXIGÊNCIAS NUTRICIONAIS DE AVES E SUÍNOS, 2., 2005, Viçosa, MG. Anais... Viçosa, MG: Universidade Federal de Viçosa, 2005. p.293-314.

MELCHIOR, D.; SÈVE, B.; LE FLOC'H, N. Chronic lung inflammation affects plasma amino acid concentrations in pigs. Journal of Animal Science, v.82, p.1091-1099, 2004.

NATIONAL RESEARCH COUNCIL - NRC. Nutrient requirements of fish. Washington, D.C.: National Academy of Science, 1993. 105p.

NOBLET, J. Avaliação energética em suínos. In: WORKSHOP LATINO-AMERICANO AJINOMOTO BIOLATINA DE NUTRIÇÃO DE AVES E SUÍNOS, 2001, Foz do Iguaçu. Anais... Foz do Iguaçu: 2001. p.2-17.

ORLANDO, U.A.D.; OLIVEIRA, R.F.M.; DONZELE, J.L. et al. Níveis de proteína bruta e suplementação de aminoácidos em rações para leitoas mantidas em ambiente de conforto térmico dos 30 aos 60 kg. Revista Brasileira de Zootecnia, v.34, n.1, p.134-141, 2005.

PEZZATO, L.E.; MIRANDA, E.C.; BARROS, M.M. et al. Digestibilidade aparente de ingredientes pela tilápia-do-nilo (Oreochromis niloticus). Revista Brasileira de Zootecnia, v.31, n.4, p.1595-1604, 2002.

RODEHUTSCORD, M.; BORCHERT, F.; GREGUS, K. et al. Availability and utilization of free lysine in rainbow trout Oncorhynchus mykiss. 1. Effect of dietary crude protein level. Aquaculture, v.187, p.163-176, 2000.

ROLLIN, X.; MAMBRINI, M.; ABBOUDI, T. et al. The optimum dietary indispensable amino acid pattern for growing Atlantic salmon (Salmo salar L.) fry. British Journal of Nutrition, v.90, p.865-876, 2003

ROSTAGNO, R.S.; ALBINO, L.F.T.; DONZELE, J.L. et al. Tabelas brasileiras para aves e suínos: composição de alimentos e exigências nutricionais. Viçosa, MG: Universidade Federal de Viçosa, 2000. 141p.

SCHUHMACHER, A.; WAX, C.; GROPP, J.M. Plasma amino acids in rainbow trout (Oncorhynchus mykiss) fed intact protein or a crystalline amino acid diet. Aquaculture, v.151, p.15-28, 1997.

SILVA, D.J.; QUEIROZ, A.C. Análise de alimentos (métodos químicos e biológicos). 3.ed. Viçosa, MG: Universidade Federal de Viçosa, 2002. 235p.

SUGIURA, S.H.; GABAUDAN, J.; DONG, F.M. et al. Dietary microbial phytase supplementation and utilization of phosphorus, trace minerals and protein by rainbow trout Oncorhynchus mykiss (Walbaum) fed soybean meal-based diets. Aquaculture Research, v.32, p.583-592, 2001.

TANTIKITTI, C.; MARCH, B.E. Dynamics of plasma free amino acids in rainbow trout (Oncorhynchus mykiss) under variety of dietary conditions. Fish Physiology and Biochemistry, v.14, p.179-194, 1995. 
UNIVERSIDADE FEDERAL DE VIÇOSA - UFV. Sistemas de Análises Estatísticas e Genéticas - SAEG. Versão 8.0. Viçosa, MG: 1997. (CD-ROM).

YAMAMOTO, T.; SUGITA, T.; FURUITA, H. Essential amino acid supplementation to fish meal-based diets with low protein to energy ratios improves the protein utilization in juvenile raimbow trout Oncorhinchus mykiss. Aquaculture, v.246, n.1-4, p.379-391, 2005.
ZARATE, D.D.; LOVELL, R.T. Free lysine (L-lysine - $\mathrm{HCl}$ ) is utilized for growth less efficiently than protein-bound lysine (soybean meal) in practical diets by young channel catfish (Ictalurus punctatus). Aquaculture, v.159, p.87-100, 1997.

ZARATE, D.D.; LOVELL, R.T; PAYNE, M. Effects of feeding frequency and rate of stomach evacuation on utilization of dietary free and protein-bound lysine for growth by channel catfish Ictalurus punctatus. Aquaculture Nutrition, v.5, p.17-22, 1999. 